\title{
Indomethacin Fails to Induce Ulceration in the Gastrointestinal Tract of Newborn and Suckling Rats
}

\author{
ALAN D. BEDRICK AND PHILIP G. HOLTZAPPLE \\ Departments of Medicine and Pediatrics, State University of New York-Upstate Medical Center, Syracuse, New \\ York 13215 and Department of Pediatrics, University of Arizona Health Sciences Center, Tucson, Arizona 85724
}

\begin{abstract}
Little is known about the role of oral prostaglandins and maintenance of intestinal epithelial cell membrane integrity in suckling animals. The presence of prostaglandins in milk suggests that they may have potential cytoprotective effects. Thus, experiments were performed to determine whether indomethacin causes inflammation in the gastrointestinal tract of suckling animals. Rats were treated with daily intraperitoneal injections of indomethacin $(10 \mathrm{mg} / \mathrm{kg})$ starting on the 1 st day of life. Unlike adult animals which develop intestinal lesions within $72 \mathrm{~h}$, these rats did not develop intestinal ulcerations until weaning started on days 15 to 16 . Indomethacintreated suckling animals prevented from weaning did not develop intestinal lesions until they had access to solid food on day 23. Indomethacin-treated rats had large reductions in jejunal prostaglandin $\mathrm{E}_{2}$ content. In addition, prostaglandin $E_{2}$ was present in rat milk in relatively large concentration as determined by radioimmunoassay. These studies suggest that exogenous prostaglandins present in milk may protect the intestine of suckling rats from indomethacin-induced inflammation; however, once weaning commences, prostaglandin insufficiency may develop leading to intestinal lesions. We speculate that suckling rats treated with indomethacin did not develop ulcerative lesions, despite a marked reduction in intestinal prostaglandin content, possibly due to prostaglandins present in milk. (Pediatr Res 20: 598-601, 1986)
\end{abstract}

Nonsteroidal antiinflammatory agents such as indomethacin produce intestinal lesions in adult rats consisting of perforating ulcers of the jejunoileum resulting in peritonitis and death in 23 days. These lesions appear to be due to a relative prostaglandin deficiency because concomitant administration of exogenous prostaglandin completely prevents their formation $(1,2)$. This phenomenon, called "cytoprotection," relates to the ability of prostaglandins to protect the mucosa of the gastrointestinal epithelium against a variety of agents which have the capability of producing cellular damage and necrosis. This property is independent of prostaglandin inhibition of gastric acid secretion (3).

Milk, both bovine and human, contains prostaglandins. Prostaglandins $E_{2}$ and $F_{2 \alpha}$ have been identified in human milk. Prostaglandin metabolites thromboxane $\mathrm{B}_{2}$ and 6-keto prosta-

Received August 15, 1985; accepted February 18, 1986.

Address correspondence to Alan D. Bedrick, M.D., Department of Pediatrics, Section of Perinatal and Nutritional Sciences, University of Arizona Health Sciences Center, Tucson, AZ 85724.

This research was supported in part by a grant from Wyeth Laboratories, Inc. and was presented at the Annual Meeting of the Society for Pediatric Research, Washington, D.C., May 1983. glandin $F_{1 \alpha}$ have also been found in significant amounts, suggesting that milk contains the parent compounds thromboxane $\mathrm{A}_{2}$ and prostacyclin (4-6). They are also found in commercially obtained whole milk and low-fat milk (7), but not in infant formulas (6). Prostaglandin in milk has been demonstrated to be effective in promoting healing of peptic ulcers and in protecting the gastroduodenal mucosa against experimentally induced ulcers (7). In addition, administration of oral prostaglandin $E_{2}$ to humans has been demonstrated to protect the gastrointestinal mucosa from blood loss induced by indomethacin (8). Thus, considerable information exists about the importance of oral prostaglandins in maintaining integrity of the gastrointestinal epithelial cell membrane in adults. However, very little is known about similar functions of prostaglandins in suckling animals. The presence of prostaglandins in milk suggest that they may play an important role in the function and adaptation of the gastrointestinal tract to extrauterine life. The significance of prostaglandin cytoprotection in the gastrointestinal tract of stressed newborns has not been determined. Exogenous prostaglandin in breast milk could have cytoprotective effects on the gastrointestinal tract. Thus, to evaluate the role of oral prostaglandins in maintenance of gastrointestinal mucosal integrity in suckling animals, experiments were performed in suckling rats to explore whether indomethacin causes inflammation in the immature gastrointestinal tract. A preliminary report has been published (9).

\section{METHODS}

Timed pregnant Sprague-Dawley rats were allowed to deliver in an environmentally controlled animal facility. Animals were fed a standard laboratory Chow (Formulab, Purina, St. Louis, $\mathrm{MO}$ ). On the 1 st day of life, litter sizes were reduced to eight pups per dam. Pups in the same litter were then randomly divided into two treatment groups of four animals each.

Experiment $I$. One group received daily intraperitoneal injections of $0.01 \mathrm{ml}$ of indomethacin solution $(10 \mathrm{mg} / \mathrm{kg})$ while litter mate controls received phosphate buffered saline vehicle only $\left(0.02 \mathrm{M} \mathrm{K}_{2} \mathrm{HPO}_{4}-0.9 \% \mathrm{NaCl}, \mathrm{pH}=7.4\right) ; n=30$ in each treatment group. Pups remained with the mother and were allowed to wean naturally. Animals were examined and body weight was determined daily. The peritoneal cavity was inspected by the authors in all animals that died. In addition, some ill appearing animals were also sacrificed in order to examine the peritoneal contents. [In preliminary studies, we found that a single administration of $2-4 \mathrm{mg} / \mathrm{kg}$ of indomethacin resulted in intestinal inflammation within $72 \mathrm{~h}$ in adult animals of both sexes in our strain $(n=12)$, a result that is in agreement with other investigators (2). A larger dose of indomethacin $(10 \mathrm{mg} /$ $\mathrm{kg}$ ) was chosen for daily administration to sucklings in order to maximize the potential development of the intestinal lesion.] 
Experiment II. To examine the effect of delayed weaning to a solid diet on the development of indomethacin-induced intestinal inflammation, experiments were conducted in pups in which free access to a solid diet was prevented. Food was removed from cages housing mothers and pups on day 15 although water in drinking bottles was available ad libitum. Mothers and sucklings were placed in wire mesh cages to prevent coprophagia and consumption of wood chip bedding material. Pups were not permitted access to solid Chow until day 23. Mothers were removed twice daily for a 3-h period (0700-1000 and 1900-2200 h) to allow food consumption. Indomethacin was administered to one-half of the pups as described above; $n=30$ in each treatment group.

Experiment III. Determination of prostaglandin $\mathrm{E}_{2}$ content in rat milk was performed as follows: milk was collected from lactating rats $(n=10) 10$ days after delivery. Pups were removed for $2 \mathrm{~h}$, mothers were sedated with pentobarbital $(2 \mathrm{mg} / \mathrm{kg})$, and then administered $1 \mathrm{U}$ of oxytocin subcutaneously. Gentle mammary gland massage was then performed to obtain milk that was collected with a microcapillary pipette. Milk was stored at $-20^{\circ}$ $\mathrm{C}$ until analysis.

Experiment IV. Radioimmunoassay determination of prostaglandin $E_{2}$ in jejunal tissue was performed in indomethacintreated and control animals at ages 1, 10, and 90 days. Animals 1 and 90 days of age received a single intraperitoneal dose of indomethacin $(10 \mathrm{mg} / \mathrm{kg}) 2 \mathrm{~h}$ prior to sacrifice. Ninety-day-old rats were fasted for $24 \mathrm{~h}$ with free access to water only prior to indomethacin treatment. This time period was found to allow almost complete emptying of food contents from the gastrointestinal tract. Animals aged 10 days received daily injections of $10 \mathrm{mg} / \mathrm{kg}$ of indomethacin from birth with the last dose $2 \mathrm{~h}$ prior to sacrifice. Control animals received phosphate-buffered saline vehicle on the same schedule. Rats were killed by decapitation at $1000 \mathrm{~h}$ and the small intestine removed immediately and divided along its length into three equal segments. The middle segment was flushed with ice cold phosphate buffered saline, $\mathrm{pH}$ $=7.4$, immediately immersed in liquid nitrogen, and stored in the vapor phase until analysis.

Prostaglandin $\mathrm{E}_{2}$ content was determined by radioimmunoassay using modification of the techniques of Green et al. (10). Frozen tissue was minced with a scissors and $10 \%(\mathrm{w} / \mathrm{v})$ whole tissue homogenates were prepared with a motor-driven Teflon piston in ice cold $0.9 \% \mathrm{NaCl}$, adjusted to $\mathrm{pH}=2$ with $0.1 \mathrm{~N}$ $\mathrm{HCl}$. The $\mathrm{pH}$ was then adjusted to 3.5 with $0.1 \mathrm{~N} \mathrm{HCl}$. This homogenate was then diluted with acid saline, $\mathrm{pH}=3.5$, to make a $1 \%(\mathrm{w} / \mathrm{v})$ homogenate. Following addition of $1000 \mathrm{cpm}$ of tritiated prostaglandin $E_{2}$ to $1 \mathrm{ml}$ aliquots of the $1 \%$ homogenate to monitor extraction efficiency, two extractions with $5 \mathrm{ml}$ of ethyl acetate were performed. The ethyl acetate phases were combined and dried under nitrogen stream at $40^{\circ} \mathrm{C}$. Residues were applied to a $700 \mathrm{mg}(7 \mathrm{~mm}$ internal diameter; $40 \mathrm{~mm}$ height) column of 100-200 mesh silicic acid. The column was then washed with $1 \mathrm{ml}$ of benzene followed by $4 \mathrm{ml}$ of benzene:ethyl acetate (60:40). Prostaglandin $\mathrm{E}_{2}$ was then eluted with $13 \mathrm{ml}$ of benzene:ethyl acetate:methanol $(60: 40: 2)$ and dried under nitrogen stream at $40^{\circ} \mathrm{C}$. Radioactive tracer prostaglandin and specific antiserum to prostaglandin $E_{2}$ were reconstituted in phosphate-buffered saline containing $1 \%$ gelatin and added to tissue extracts. After an 18-h incubation at $4^{\circ} \mathrm{C}$, dextran-coated charcoal was added, and following a 10 -min centrifugation at $1000 \times g$ at room temperature the supernatant was transferred into vials containing $10 \mathrm{ml}$ of scintillation fluid and radioactivity quantitated for $10 \mathrm{~min}$ in a liquid scintillation counter. Prostaglandin content is expressed as $\mathrm{pg} / \mathrm{mg}$ of protein. Samples were analyzed in a single batch as frequently as possible to minimize interassay variation. Extraction efficiency was $70-80 \%$. Protein determinations were performed according to the method of Lowry et al. (11).

Prostaglandin $\mathrm{E}_{2}$ extraction of milk samples was performed as noted above with slight modification. Two hundred $\mu$ l of milk was thawed and placed in a conical glass vial to which acid phosphate-buffered saline ( $\mathrm{pH}=2$ ) was added to bring the total volume to $1 \mathrm{ml}$. Following sample extraction and application to the silicic acid column, $2 \mathrm{ml}$ of benzene were used to wash the sample and column initially. Prostaglandin $\mathrm{E}_{2}$ elution and radioimmunoassay was then performed as outlined.

Metabolism of prostaglandin $\mathrm{E}_{2}$ in the gastrointestinal tract has been widely studied $(12,13)$. Therefore, this compound was chosen as a representative prostaglandin for radioimmunoassay quantitation in intestinal tissue and milk.

\section{SUPPLIES}

Prostaglandin $\mathrm{E}_{2}$ standard and antiserum were obtained from Sigma Chemical Company, St. Louis, MO. Radioisotope and Biofluor scintillation counting fluid were purchased from New England Nuclear Company, Boston, MA. Silicic acid (BioSil A) was obtained from Bio-Rad Company, Richmond, CA.

\section{STATISTICAL ANALYSIS}

The significance of the difference in the mean values of groups was evaluated by the $t$ test for unpaired values.

\section{RESULTS}

Experiment $I$. For the first 16 days of life, the growth pattern of suckling rat pups treated with indomethacin was identical to that of littermate controls. Coincident with the start of weaning (14), indomethacin-treated animals became less vigorous by days 17 to 18 , began to lose weight, and all died by days 20 to 21 (Fig. 1). Examination of the peritoneal contents revealed extensive intestinal inflammation with ulceration, adhesions, and peritonitis. These findings were present in all dead animals and also in those sacrificed due to severe illness on days 19 to 20. This lesion was similar to that seen in adult animals treated once with indomethacin at a dose of $10 \mathrm{mg} / \mathrm{kg}$. The gastric mucosa appeared normal. There were no indomethacin-treated suckling animals without intestinal lesions. No gastrointestinal lesions were observed in saline treated sucklings.

Experiment II. Suckling rats subjected to delayed weaning grew less than those allowed access to solid food, probably due to lower caloric intake. However, the growth curve of indomethacin-treated pups was identical to littermate controls (Fig. 1); no intestinal lesions were found in these rats up to day 23 . Once allowed access to solid food on day 23 , these animals developed ulcerations as described above and died within 3-4 days.

Experiments III and IV. The results of determinations of

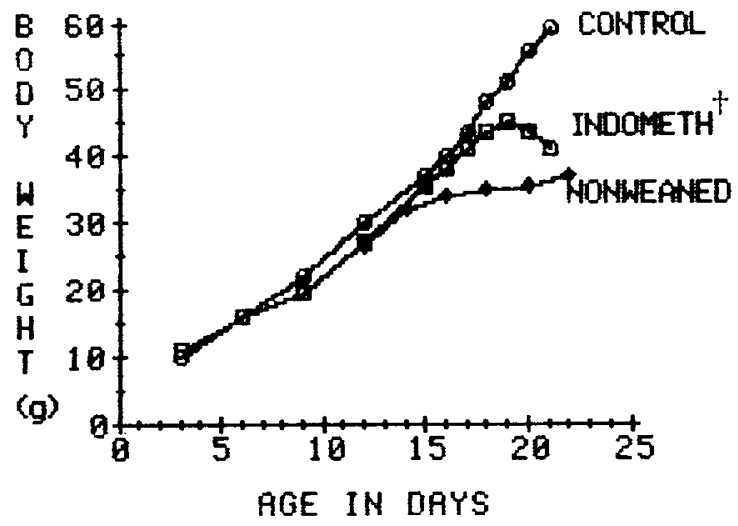

Fig. 1. Growth curves for indomethacin- and saline-treated rats. Growth curves for nonweaned (control and indomethacin-treated) animals were identical and are superimposed. $O$, control-regular weaning; $\square$, indomethacin-treated-regular weaning; $\bullet$, control/indomethacintreated-nonweaned; $\dagger$, death; $n, 30$ in each experimental group. 
jejunal prostaglandin content are seen in Table 1 . These data clearly demonstrate an age-related increase in jejunal prostaglandin content. Mid-jejunal prostaglandin $\mathrm{E}_{2}$ content tended to be higher in 10-day-old animals in comparison to 1-day-old animals; further prostaglandin $\mathrm{E}_{2}$ content was significantly higher $(p<0.01)$ in 90 -day-old animals in comparison to both younger age groups. Treatment with indomethacin resulted in greater than $90 \%$ reduction in prostaglandin content $(p<0.01)$ in all age groups (Table 1)

The prostaglandin $\mathrm{E}_{2}$ content of rat milk was $180 \pm 50 \mathrm{pg} / \mathrm{ml}$ $(n=10)$.

\section{DISCUSSION}

The results of these studies suggest that exogenous prostaglandins present in breast milk may protect the intestinal mucosa of suckling rats from the ulcerogenic effects of indomethacin. Unlike adult animals, administration of large doses of indomethacin to suckling rat pups does not lead to development of intestinal ulcerations. We speculate that, despite a very large reduction in prostaglandin content, suckling rats treated with indomethacin and animals not allowed to wean naturally did not develop intestinal ulcerations due to cytoprotective exogenous prostaglandins present in milk. However, once weaning starts, a state of prostaglandin insufficiency may develop, thus leading to the intestinal lesions. Although levels of other prostaglandins were not measured in this study, other investigators have demonstrated large decreases in tissue content of other prostaglandin classes in intestinal tissue after administration of nonsteroidal antiinflammatory agents such as indomethacin $(15,16)$. It is likely, therefore, that the overall intestinal prostaglandin content of animals treated with indomethacin was decreased.

We have recently demonstrated that exogenous prostaglandins administered via orogastric tube to suckling and weanling rats can reach all segments of the small intestine in an intact, unmetabolized form (17). In addition, prostaglandins present in breast milk appear to be relatively stable. In human milk, the ratio of the concentration of a major metabolite of prostaglandins of the $\mathrm{E}$ and $\mathrm{F}$ series (the 13,14 di-hydro, 15-keto derivatives) to the intact compounds is low in comparison to plasma (5). This suggests that prostaglandin half-life in milk is relatively long in contrast to plasma. Our experimental observations suggest that oral prostaglandins exert their cytoprotective effect on the intestine via direct topical action. It is possible that the introduction of food to the diet may have contributed to the development of the ulcerations. Previous studies in adult animals have demonstrated that the solid component of food may play an important role in the formation of indomethacin-induced gastrointestinal lesions (18).

Other investigators have also noted the cytoprotective effect of milk on the gastrointestinal epithelium in experimental ulcer models in rats. Ackerman et al. (19) demonstrated that 1-monthold rats were relatively protected against restraint-induced ulcers if unrestricted suckling is allowed before weaning. Similarly aged rats reared in the presence of their mothers whose nipples were

Table 1. Rat jejunal prostaglandin $(P G) E_{2}$ content

\begin{tabular}{|c|c|c|c|}
\hline $\begin{array}{c}\text { Age } \\
\text { (days) }\end{array}$ & & $\begin{array}{c}\mathrm{PGE}_{2} \\
\text { content-control } \\
\text { (pg/mg protein) }\end{array}$ & $\begin{array}{c}\mathrm{PGE}_{2} \\
\text { content-INDO* }\end{array}$ \\
\hline $\begin{array}{r}1 \\
10 \\
90\end{array}$ & $\S\left\{\begin{array}{l}\ddagger \\
\S\end{array}\right.$ & $\left\{\begin{array}{l}154.1 \pm 13.2(12) \dagger \\
202.6 \pm 20.6(6) \\
690.9 \pm 53.4(9)\end{array}\right.$ & $\begin{array}{l}12.4 \pm 2.5(6) \\
20.1 \pm 3.2(6) \\
43.6 \pm 18.6(3)\end{array}$ \\
\hline
\end{tabular}

* Statistical significance for indomethacin-treated animals determined against appropriate controls; $p<0.01$ for all age groups.

+ Mean $\pm \operatorname{SEM}(n)$

$\ddagger$ NS.

$\S p<0.01$. ligated on day 15 were more susceptible to restraint-induced ulcers.

Indomethacin-induced intestinal lesions have been well characterized (20). Histologically, mucosal edema and inflammatory cell infiltration with ulceration and cellular necrosis are present. It is believed that the lack of cytoprotective prostaglandins allows intestinal lumenal substances, such as microorganisms, bile acids, or dietary constituents to damage intestinal cells resulting ultimately in progressive mucosal injury (1). The specific mechanisms involved in prostaglandin-mediated cytoprotection are unclear. It appears that either endogenously synthesized or exogenously derived prostaglandins, as suggested by our studies, are necessary to maintain integrity of the intestinal mucosa. Prostaglandin synthetase inhibitors such as indomethacin have been used to pharmacologically close the patent ductus arteriosus in ill newborn infants (21). Some neonatology centers have noted an increased incidence of focal perforation of the gastrointestinal tract in infants who received indomethacin (22).

In addition to prostaglandins, other substances present in breast milk may be cytoprotective for the gastrointestinal epithelium. Lichtenberger et al. (23) have shown that phospholipids present in high concentration in rat milk can protect the rat gastric mucosa from noxious agents and suggested that prostaglandin-induced cytoprotection was mediated in part by localized increases in phospholipid concentration. In an acid-induced necrosis model in neonatal rats, treatment with phospholipidcontaining rat milk afforded greater protection than treatment with synthetic prostaglandin analogues (24).

The contribution of prostaglandins to the cytoprotective effect of milk needs further study. Further evaluation of prostaglandin metabolism in the gastrointestinal tract of suckling animals needs to be performed in view of the presence of prostaglandins in human milk. Data obtained in these studies will permit a more thorough understanding of newborn intestinal physiology.

Acknowledgments. The authors thank Otakar Koldovský, M.D., Ph.D. for his helpful discussions. Lyophilized indomethacin was donated by Dr. Morten Rosenberg of Merck, Sharpe, and Dohme, Inc., West Point, PA.

\section{REFERENCES}

1. Robert A 1979 Cytoprotection by prostaglandins. Gastroenterology 77:761-

2. Robert A 1975 An intestinal disease produced experimentally by a prostaglandin deficiency. Gastroenterology 69:1045-1047

3. Miller TA 1983 Editorial review: protective effects of prostaglandins against gastric mucosal damage: current knowledge and proposed mechanisms. Am J Physiol 245:G601-G623

4. Manns JG 1975 The excretion of prostaglandin $F_{2 \alpha}$ in milk of cows. Prostaglandins 9:463-474

5. Lucas A, Mitchell MD 1980 Prostaglandins in milk. Arch Dis Child 55:950952

6. Reid B, Smith H, Friedman Z 1980 Prostaglandin in human milk. Pediatrics 66:870-872

7. Materia A, Jaffe BM, Mondy SR, Rossi P, DeMarco M, Basso N 1984 Prostaglandins in commercial milk preparations. Arch Surg 119:290-292

8. Johansson C, Kollberg B, Nordemar R, Samuelson K, Bergstrom S 1980 Protective effect of prostaglandin $E_{2}$ in the gastrointestinal tract during indomethacin treatment of rheumatic diseases. Gastroenterology 78:479483

9. Bedrick A, Starr C, Palmadessa D, Holtzapple P 1983 Indomethacin fails to produce ulceration in the neonatal intestine. Pediatr Res 17:183(abstr)

10. Green K, Hamberg M, Samuelsson B, Frolich JC 1978 Extraction and chromatographic procedures for purification of prostaglandins, thromboxanes, prostacyclin, and their metabolites. In: Frolich JC (ed). Advances in Prostaglandin Thromboxane Research, Vol 5. Raven Press, New York, pp 15-38

1. Lowry O, Rosebrough N, Farr A, Randall R 1951 Protein measurement with the folin phenol reagent. J Biol Chem 193.265-275

12. Knapp H, Olez O, Sweetman B, Oates J 1978 Synthesis and metabolism of prostaglandins $E_{2}, F_{2 \alpha}$ and $D_{2}$ by the rat gastrointestinal tract. Stimulation by a hypertonic environment in vitro. Prostaglandins 15:751-757

13. Smith G, Warhurst G, Turnberg L 1982 Synthesis and degradation of prostaglandin $E_{2}$ in the epithelial and sub-epithelial layers of the rat intestine. Biochim Biophys Acta 713:684-687

14. Hahn P, Koldovsky O 1966 The late effects of changes in the composition of the diet during the wearing period. In: pp 147-156 Utilization of Nutrients 
during Postnatal Development. Pergamon Press, Oxford, pp 147-156

15. Whittle B 1981 Arachidonic acid metabolites and the gastrointestinal toxicity of anti-inflammatory agents. Prostaglandins 21(suppl):113-119

16. Meydani S, Meydani M, Dupont J 1983 Effects of prostaglandin modifiers and zinc deficiency on possibly related functions in rats. $J$ Nutr $494-500$

17. Bedrick A, Kildovsky O 1985 Differences in processing of orally administered prostaglandin $\mathrm{F}_{2 \alpha}$ in the gastrointestinal tract and liver of suckling and weanling rats. Pediatr Res 19:212(abstr)

18. Hiroshi S, Guth P, Grossman M 1982 Role of food in gastrointestinal ulceration produced by indomethacin in the rat. Gastroenterology 83:210-215

19. Ackerman S, Hofer M, Weiner H 1978 Predisposition to gastric erosions in the rat: behavioral and nutritional effects of early maternal separation. Gastroenterology 75:649-654
20. Brodie D, Cook P, Bauer B, Dagle G 1970 Indomethacin-induced intestinal lesions in the rat. Toxicol Appl Pharmacol 17:615-624

21. Heymann M, Rudolph A, Silverman N 1976 Closure of the ductus arteriosus in premature infants by inhibition of prostaglandin synthesis. N Engl J Med 295:530-533

22. Nagaraj HS, Sandhu AS, Cook LN, Buchino JJ, Groff DB 1981 Gastrointestinal perforation following indomethacin therapy in very low birth weight infants. J Pediatr Surg 16:1003-1007

23. Lichtenberger L, Graziani L, Dial E, Butler B, Hills B 1983 Role of surfaceactive phospholipids in gastric cytoprotection. Science 219:1327-1329

24. Dial EJ, Lichtenberger LM 1984 A role for milk phospholipids in protection against gastric acid-studies in adult and suckling rats. Gastroenterology 87:379-385 